\title{
Impaired left ventricular mechanical and energetic function in mice after cardiomyocyte-specific excision of Serca2
}

\author{
N. T. Boardman, ${ }^{1}$ J. M. Aronsen, ${ }^{2,3}$ W. E. Louch, ${ }^{2,3}$ I. Sjaastad, ${ }^{2,3}$ F. Willoch, ${ }^{4}$ G. Christensen, ${ }^{2,3}$ \\ O. Sejersted, ${ }^{2,3}$ and E. Aasum ${ }^{1}$ \\ ${ }^{1}$ Cardiovascular Research Group, Department of Medical Biology, Faculty of Health Sciences, UiT The Artic University of \\ Norway, Tromsø, Norway; ${ }^{2}$ Institute for Experimental Medical Research, Oslo University Hospital and University of Oslo, \\ Oslo, Norway; ${ }^{3}$ K. G. Jebsen Cardiac Research Center and Center for Heart Failure Research, University of Oslo, Oslo, \\ Norway; and ${ }^{4}$ Preclinical PET/CT, Institute of Basic Medical Sciences, University of Oslo, Oslo, Norway
}

Submitted 26 September 2013; accepted in final form 26 January 2014

Boardman NT, Aronsen JM, Louch WE, Sjaastad I, Willoch F, Christensen G, Sejersted O, Aasum E. Impaired left ventricular mechanical and energetic function in mice after cardiomyocyte-specific excision of Serca2. Am J Physiol Heart Circ Physiol 306: H1018-H1024, 2014. First published January 31, 2014; doi:10.1152/ajpheart.00741.2013.-Sarco(endo)plasmic reticulum $\mathrm{Ca}^{2+}$-ATPase (SERCA)2 transports $\mathrm{Ca}^{2+}$ from the cytosol into the sarcoplasmic reticulum of cardiomyocytes and is essential for maintaining myocardial $\mathrm{Ca}^{2+}$ handling and thus the mechanical function of the heart. SERCA2 is a major ATP consumer in excitation-contraction coupling but is regarded to contribute to energetically efficient $\mathrm{Ca}^{2+}$ handling in the cardiomyocyte. Previous studies using cardiomyocytespecific SERCA2 knockout (KO) mice have demonstrated that decreased SERCA2 activity reduces the $\mathrm{Ca}^{2+}$ transient amplitude and induces compensatory $\mathrm{Ca}^{2+}$ transport mechanisms that may lead to more inefficient $\mathrm{Ca}^{2+}$ transport. In this study, we examined the relationship between left ventricular $(\mathrm{LV})$ function and myocardial $\mathrm{O}_{2}$ consumption $\left(\mathrm{MVO}_{2}\right)$ in ex vivo hearts from SERCA2 $\mathrm{KO}$ mice to directly measure how SERCA2 elimination influences mechanical and energetic features of the heart. Ex vivo hearts from SERCA2 KO hearts developed mechanical dysfunction at $4 \mathrm{wk}$ and demonstrated virtually no working capacity at $7 \mathrm{wk}$. In accordance with the reported reduction in $\mathrm{Ca}^{2+}$ transient amplitude in cardiomyocytes from SERCA2 KO mice, work-independent $\mathrm{MV}_{2}$ was decreased due to a reduced energy cost of excitation-contraction coupling. As these hearts also showed a marked impairment in the efficiency of chemomechanical energy transduction (contractile efficiency, i.e, workdependent $\mathrm{MV}_{\mathrm{O}_{2}}$ ), hearts from SERCA2 $\mathrm{KO}$ mice were found to be mechanically inefficient. This ex vivo evaluation of mechanical and energetic function in hearts from SERCA2 KO mice brings together findings from previous experimental and mathematical modelingbased studies and demonstrates that reduced SERCA2 activity not only leads to mechanical dysfunction but also to energetic dysfunction.

mechanical efficiency; myocardial oxygen consumption; contractile efficiency; pressure-volume area; mechanoenergetics

RELAXATION OF THE MYOCARDIUM Occurs as the cytosolic $\mathrm{Ca}^{2+}$ concentration returns to its resting level primarily through $\mathrm{Ca}^{2+}$ reuptake into the sarcoplasmic reticulum (SR) by sarco(endo)plasmic reticulum $\mathrm{Ca}^{2+}$-ATPase (SERCA)2. Thus, SERCA2 is essential for maintaining myocardial $\mathrm{Ca}^{2+}$ homeostasis and mechanical function of the heart. A reduction in the capacity or the absence of SERCA2 has been shown to lead to reduced force

Address for reprint requests and other correspondence: N. T. Boardman, Cardiovascular Research Group, Dept. of Medical Biology, Faculty of Health Sciences, Univ. of Troms $\varnothing$, Troms $\varnothing$ N-9037, Norway (e-mail: neoma.boardman @uit.no). generation, delayed relaxation, and advanced onset of heart failure $(3,11,27)$, whereas increased SERCA2 expression (transgenic mice and/or adenovirus-mediated overexpression) has been shown to increase cardiac function in the normal and failing heart $(28,39)$ as well as to protect against ischemiareperfusion $(12,31)$ and pressure overload $(28,35)$.

Myocardial SERCA2 activities are driven by ATP, and, as the majority of cytosolic $\mathrm{Ca}^{2+}$ is pumped back into the SR by SERCA2, this mechanism is the major energy consumer in $\mathrm{Ca}^{2+}$ handling during excitation-contraction coupling (ECC) compared with sarcolemmal $\mathrm{Ca}^{2+}$ transport [i.e., plasma membrane $\mathrm{Ca}^{2+}$ ATPase (PMCA) and $\mathrm{Na}^{+} / \mathrm{Ca}^{2+}$ exchanger (NCX)1] (42). Metabolic and energetic studies have reported altered myocardial substrate utilization (7) and an improved postischemic energetic state (phosphocreatine-to-ATP ratio) (31) after SERCA overexpression. Examination of left ventricular (LV) mechanoenergetics has revealed that increased SERCA2 expression reduced the $\mathrm{O}_{2}$ cost of LV contractility, whereas it did not alter work-dependent and -independent $\mathrm{O}_{2}$ consumption (34). The metabolic and energetic effects of SERCA2 elimination, however, are less known. Based on the stoichiometry of each $\mathrm{Ca}^{2+}$ transporter in the cardiomyocyte [SERCA, 2 $\mathrm{Ca}^{2+}: 1 \mathrm{ATP}$; PMCA, $1 \mathrm{Ca}^{2+}: 1 \mathrm{ATP}$; and NCX1 coupled to $\mathrm{Na}^{+}-\mathrm{K}^{+}$ATPase (NKA), $\left.1 \mathrm{Ca}^{2+}: 1 \mathrm{ATP}\right], \mathrm{SR} \mathrm{Ca}^{2+}$ release and uptake (the latter by SERCA2) are regarded as the most energetically efficient. As decreased $\mathrm{Ca}^{2+}$ handling by SERCA2 will decrease SR $\mathrm{Ca}^{2+}$ content and induce compensatory mechanisms (enhanced $\mathrm{Ca}^{2+}$ fluxes through L-type $\mathrm{Ca}^{2+}$ channels as well as an increased presence of sarcolemmal $\mathrm{Ca}^{2+}$-ATPase and NCX) $(3,14,25,38)$, there is a reason to believe that decreased SERCA2 activity/levels will affect the mechanoenergetic features of the heart. In cardiomyocytes from mice with inducible cardiomyocyte-specific excision of the Atp2a2 (Serca2) gene, the amplitude of $\mathrm{Ca}^{2+}$ transients are reduced and the decay rates are prolonged $(3,5)$. Using mathematical modeling to calculate ATP used for ion transport based on the recorded changes in intracellular ion concentrations $\left(\mathrm{Ca}^{2+}, \mathrm{Na}^{+}\right.$, and $\left.\mathrm{H}^{+}\right)$and $\mathrm{Ca}^{2+}$-handling protein levels/activity from these cardiomyocytes, Li et al. (23) suggested that the ATP cost for ion transport was initially decreased followed by an increase at a later stage when the hearts present signs of heart failure $(3,5)$. It should also be noted, however, that the stoichiometry of SERCA2 has been suggested to be reduced when $\mathrm{SR} \mathrm{Ca}{ }^{2+}$ is elevated (43), and as the mathematical model by Li et al. (23) did not include work-dependent ATP utilization (contractile efficiency), the aim of the present study was to examine the relationship between cardiac work and $\mathrm{O}_{2}$ consumption in 
hearts from SERCA2 knockout (KO) mice. This allows for a direct assessment of the influence of SERCA2 elimination on mechanical efficiency, the energy cost for ECC and basal metabolism, as well as the efficiency of chemomechanical energy transduction (i.e., contractile efficiency).

\section{METHODS}

Animals. Serca2 flox/flox (SERCA2 FF) and Serca2 flox/flox $\mathrm{Tg}$ ( $\alpha$ MHC-MerCreMer) (SERCA2 KO) mice, backcrossed onto the B6/J background, have been previously described $(3,5)$. The resulting adult SERCA2 KO mice do not present any abnormalities until rapid disruption of the Atp2a2 (Serca2) gene is induced by tamoxifen, whereas control SERCA2 FF mice remain unaffected $(3,5,6)$. Mice aged $8-10$ wk were injected once intraperitoneally with tamoxifen (40 $\mathrm{mg} / \mathrm{kg}$, dissolved in peanut oil) for the induction of myocardial Serca 2 excision, a dose that has also been shown to prevent the transient tamoxifen-induced cardiomyopathy previously observed in transgenic $\alpha$ MHC-MerCreMer mice (17).

All mice were housed in a room maintained at $21^{\circ} \mathrm{C}$ and $55 \%$ humidity with a 12:12-h light-dark cycle and were given ad libitum access to food and water. Mice were treated in accordance with guidelines on the accommodation and care of animals formulated by the European Convention for the Protection of Vertebrate Animals for Experimental and Other Scientific Purposes. Experiments were approved by the Animal Welfare Committee of the University of Tromsø.

Isolated heart perfusions. Mice were euthanized, and hearts excised for experiments at 4 or 7 wk after tamoxifen injection. After anesthesia (10 mg ip injection of pentobarbital sodium), hearts were excised, and the aorta was cannulated with an 18-gauge cannula. Hearts were perfused in the working or retrograde mode as previously described (9). Modified Krebs-Henseleit bicarbonate buffer containing $2.5 \mathrm{mM} \mathrm{Ca}^{2+}$ was supplemented with glucose $(5 \mathrm{mM})$ and palmitate $(0.7 \mathrm{mM}$, bound to $3 \%$ BSA) $(1,9)$ as the energy substrate, and substrate oxidation was determined by the collection of ${ }^{14} \mathrm{CO}_{2}$ and ${ }^{3} \mathrm{H}_{2} \mathrm{O}$ released by the oxidation of $\left[\mathrm{U}^{1}{ }^{14} \mathrm{C}\right]$ glucose and $[9,10-$ ${ }^{3} \mathrm{H}$ ]palmitate, respectively (1).

LV mechanical function was assessed using a 1.4-Fr conductance catheter (Millar Instruments, Houston, TX) inserted in the LV through the apex in electrically paced hearts $(7 \mathrm{~Hz})$. Hearts were exposed to different work loads by changing the preload (from 4 to $10 \mathrm{mmHg}$ ) and afterload (from 40 to $50 \mathrm{mmHg}$ ), and steady-state functional and contractile parameters were analyzed at various work loads (18).

Energy expenditure of the heart was determined as myocardial $\mathrm{O}_{2}$ consumption $\left(\mathrm{MV}_{\mathrm{O}_{2}}\right)$ and was calculated based on measurements using the difference in $\mathrm{O}_{2}$ content in the buffer entering and leaving the heart and the coronary flow $(2,9,15) . \mathrm{MV}_{2}$, stroke work [the area within the pressure-volume (P-V) loop], and P-V area (PVA; representing the total cardiac work) (18) was calculated at each work load. Mechanical efficiency, which connotes the efficiency by which the heart performs external work, was calculated as the ratio between stroke work and $\mathrm{MV}_{2}$ (8). Regression analysis of the relationship between PVA and $\mathrm{MVO}_{2}$ allowed for the determination of contractile efficiency (the inverse slope of this relationship) (40). Work-independent $\mathrm{MVO}_{2}$ was measured in the retrograde perfused unloaded heart $\left(\mathrm{MV}_{2}\right.$ unloaded). By electrically arresting these hearts (elevation of extracellular $\mathrm{K}^{+}$concentration), we could also measure the $\mathrm{O}_{2}$ cost of basal metabolism $\left(\mathrm{MV}_{2} \mathrm{BM}\right)$, and the difference between $\mathrm{MV}_{\mathrm{O}_{2}}$ unloaded and $\mathrm{MV}_{\mathrm{O}_{2}} \mathrm{BM}$ was used to obtain the $\mathrm{O}_{2}$ cost of ECC $\left(\mathrm{MV}_{2}\right.$ ECC $)(2,9,10,15)$.

Fluorodeoxyglucose uptake with a small animal positron emission tomography scanner. A small animal positron emission tomography (PET) scanner (microPET Focus 120, Concorde-CTI/Siemens, Knoxville, TN) was used to measure fluorodeoxyglucose $\left({ }^{18} \mathrm{FDG}\right.$; SteriPET, GE Healthcare, Oslo, Norway) uptake in cardiac tissue in mice $5 \mathrm{wk}$ after tamoxifen injection. Food was removed $2 \mathrm{~h}$ before the experiment. Anesthesia was induced and maintained with $2 \%$ isoflurane and reduced to $1.5 \%$ isoflurane during the PET scanning. ${ }^{18} \mathrm{FDG}$ $(8 \sim 10 \mathrm{MBq}, 0.1 \mathrm{ml})$ was injected intraperitonally $30 \mathrm{~min}$ before scanning in resting mice. Scanning time was $20 \mathrm{~min}$ with a 10 -min transmission scan afterward for attenuation correction. Computed tomography (CT) scans were performed using microCAT (Micro CAT II, Imtek/Siemens), and a three-dimensional static image was reconstructed using the OSEM3D/MAP algorithm (2 OSEM3D iterations, 18 MAP iterations, $\beta$-value of 0.15$)$. The matrix size was $128 \times 128 \times 95$, and the image voxel size was $0.87 \times 0.87 \times 0.87$ $\mathrm{mm}^{3}$. All data analysis was done using the PMOD software package (PMOD Technologies, Zurich, Switzerland). PET images were coregistered with the corresponding CT images. The apical half of the heart as the volume of interest was manually delineated from the CT images. The standard uptake value in the volume of interest was then obtained from the coregistered PET images and interpreted as ventricular ${ }^{18}$ FDG uptake.

$m R N A$ expression/real-time quantitative $R T-P C R$. LV samples were immersed in RNAlater (Qiagen, Hilden, Germany), and total RNA was extracted according to the recommendations in the RNeasy Fibrous Tissue protocol (Qiagen). The RNA concentration was measured spectrophotometrically (NanoDrop, Witec, Switzerland) and stored at $-80^{\circ} \mathrm{C}$ before use. cDNA was obtained from $1 \mu \mathrm{g}$ total RNA, and quantitative PCR was performed in an ABI PRISM 7900 HT Fast real-time thermal cycler using a 1:4 dilution of the cDNA and TaqMan Fast Universal PCR master mix (Applied Biosystems, Foster City, CA). Hypoxanthine phosphoribosyltransferase 1 (Hbrt1) was used as a housekeeping gene. Primer/probe sequences for Serca2, brain natriuretic peptide (Bnp), and myosin heavy chain- $\alpha$ and $-\beta$ (Mhc- $\alpha$ and $M h c-\beta$, respectively) have been previously described (16).

Statistical analysis. All data are expressed as means \pm SE. Differences between SERCA2 FF and SERCA2 KO mice were analyzed using an unpaired $t$-test. $P$ values of $<0.05$ were considered significant.

\section{RESULTS}

Animals. In agreement with previous studies (3, 25), we found that $4 \mathrm{wk}$ after the injection of tamoxifen, myocardial mRNA expression of the Atp2a2 (Serca2) gene was reduced by $95 \%$ and remained the same at $7 \mathrm{wk}$ (Table 1$)$. There were no differences in total body weight between SERCA2 FF and KO mice at 4 or $7 \mathrm{wk}$ after the injection of tamoxifen. Despite a previously reported progressive left atrial dilatation and cardiac enlargement $(3,25)$, the LV-to-body weight ratio was reduced. At both 4 and $7 \mathrm{wk}$, SERCA2 KO hearts demonstrated a small but significant increase in the lung-to-body weight ratio (Table 1). Myocardial mRNA expression of Bnp was unchanged, whereas expression of $M h c-\beta$ (but not $M h c-\alpha$ ) was increased (Table 1). This may suggest a reexpression of fetal genes that are a hallmark for the development of heart failure (33).

$L V$ mechanical function. Of the 19 SERCA2 KO hearts perfused 4 wk after Serca 2 excision, 10 hearts showed marked signs of myocardial dysfunction during the initial phase of the perfusion (up to $15 \mathrm{~min}$ ) and 4 hearts could not maintain sufficient external work (i.e., perfusion pressure equal to an afterload high of $50 \mathrm{mmHg}$ in the aortic output line). These four hearts were therefore not included in the evaluation of heart function and mechanoenergetics in the SERCA2 KO group. In the control group, stable heart function was demonstrated almost immediately (within $2 \mathrm{~min}$ ) in all hearts. Steadystate LV P-V loops were obtained using a conductance catheter in the LV, and a leftward shift of the LV P-V loop was observed in SERCA2 KO hearts (Fig. 1 and Table 2). SERCA2 
Table 1. Body weight, LV weight, lung weight, and cardiac gene expression in SERCA2 FF and SERCA2 KO mice

\begin{tabular}{|c|c|c|c|c|}
\hline & \multicolumn{2}{|c|}{4 Weeks } & \multicolumn{2}{|c|}{7 Weeks } \\
\hline Number of mice & 15 & 19 & 10 & 12 \\
\hline LV weight/body weight, \% & $0.38 \pm 0.01$ & $0.36 \pm 0.01 *$ & $0.35 \pm 0.01$ & $0.33 \pm 0.01 *$ \\
\hline Lung weight/body weight, $\%$ & $0.56 \pm 0.01$ & $0.60 \pm 0.01 *$ & $0.53 \pm 0.01$ & $0.56 \pm 0.01 *$ \\
\hline \multicolumn{5}{|l|}{ mRNA expression } \\
\hline Myosin heavy chain - $\alpha$ & $1 \pm 0.05$ & $1.11 \pm 0.06$ & $1 \pm 0.05$ & $0.97 \pm 0.03$ \\
\hline Myosin heavy chain - $\beta$ & $1 \pm 0.07$ & $1.81 \pm 0.23 *$ & $1 \pm 0.15$ & $3.69 \pm 0.76^{*}$ \\
\hline
\end{tabular}

Values are means \pm SE. LV, left ventricular; SERCA2, sarco(endo)plasmic reticulum $\mathrm{Ca}^{2+}$-ATPase; SERCA2 FF mice, Serca $2^{\text {floxfflox }}$ mice; SERCA2 KO mice, SERCA2 knockout mice. $* P<0.05$ vs. SERCA2 FF mice.

KO hearts demonstrated decreased cardiac output and stroke work as well as reduced LV systolic pressure and $\mathrm{dP} / \mathrm{d} t_{\max }$ (Table 2). SERCA2 KO hearts also demonstrated impaired LV relaxation, as indicated by an elevated relaxation factor and decreased $\mathrm{dP} / \mathrm{d} t_{\min }$ (Table 2). These parameters of diastolic dysfunction were, however, not associated with increased LV end-diastolic pressure. Finally, coronary flow was found to be reduced in SERCA2 KO hearts at the 4-wk time point.

Hearts from SERCA2 KO mice at $7 \mathrm{wk}$ after the excision of Serca 2 showed very low ex vivo functional capacity, i.e., three of six SERCA2 KO hearts were not able to maintain a perfusion pressure equal to an afterload high of $50 \mathrm{mmHg}$ in the aortic output line (data not shown). In another group of hearts, we increased the perfusate $\mathrm{Ca}^{2+}$ concentration to $5 \mathrm{mM}$ and found that, again, three of six SERCA2 KO hearts maintained afterload pressure (data not shown). Hearts from age-matched control mice showed normal function under both conditions.

$L V$ energetic function. Total energy expenditure (assessed by measuring $\mathrm{MV}_{\mathrm{O}_{2}}$ ), stroke work (area of the $\mathrm{P}-\mathrm{V}$ loop), and total mechanical energy (PVA) were measured under different loading conditions. These measurements were used to evaluate mechanical efficiency and the efficiency of the chemomechanical energy transduction (contractile efficiency). Figure $2 \mathrm{~A}$ shows the relationship between $\mathrm{MV}_{\mathrm{O}_{2}}$ and stroke work at three

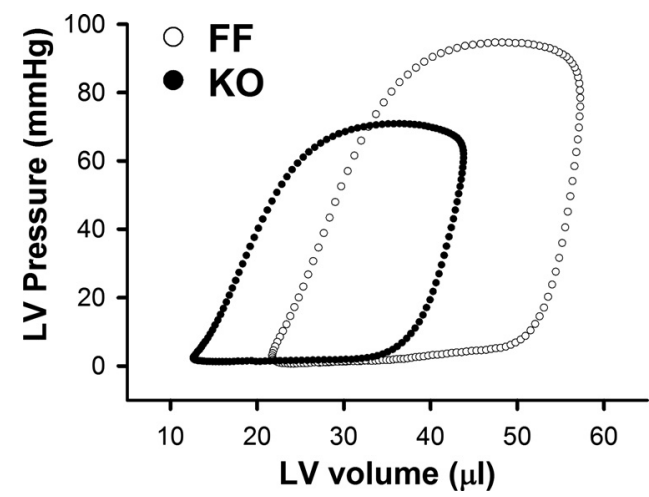

Fig. 1. Representative pressure-volume recording in ex vivo perfused hearts (preload: $10 \mathrm{mmHg}$; afterload: $50 \mathrm{mmHg}$ ) from sarco(endo)plasmic reticulum $\mathrm{Ca}^{2+}$-ATPase 2 (Serca2) floxfflox $(\mathrm{FF})$ and SERCA2 knockout (KO) mice $4 \mathrm{wk}$ after Serca2 gene excision. LV, left ventricular. different workloads at the 4-wk time point. We found SERCA2 $\mathrm{KO}$ hearts to have a relatively higher $\mathrm{MV}_{\mathrm{O}_{2}}$ at all workloads, demonstrating a marked decrease in mechanical efficiency (stroke work/ $\mathrm{MV}_{\mathrm{O}_{2}}$ ) in SERCA2 KO hearts compared with SERCA2 FF hearts (Fig. 2B). We also examined the efficiency of the chemomechanical energy transduction through analysis of the relationship between total mechanical energy (PVA) and $\mathrm{O}_{2}$ consumption (Fig. 3A). The slope of this relationship was found to be 1.5 -fold higher in SERCA2 KO hearts compared with SERCA2 FF hearts (Fig. 3A, inset), which demonstrates that SERCA2 KO hearts show decreased contractile efficiency (1/slope) (40). $\mathrm{MV}_{\mathrm{O}_{2}}$ was also measured in mechanically unloaded retrogradely perfused hearts $\left(\mathrm{MV}_{\mathrm{O}_{2}}\right.$ unloaded $)$ to determine work-independent $\mathrm{MV}_{\mathrm{O}_{2}}$ (i.e., the $\mathrm{O}_{2}$ consumption required for nonmechanical processes). At 4 wk, SERCA2 KO hearts showed reduced $\mathrm{MVO}_{2}$ unloaded (Fig. 3B). This reduction in $\mathrm{MV}_{\mathrm{O}_{2}}$ unloaded was not found to be due to a decreased cost of basal metabolism $\left(\mathrm{MV}_{\mathrm{O}_{2} \mathrm{BM}}\right)$ but rather to a $30 \%$ reduction in $\mathrm{MV}_{\mathrm{O}_{2}} \mathrm{ECC}$ in SERCA2 $\mathrm{KO}$ hearts.

Taken together, we found that at $4 \mathrm{wk}$, despite the reduced $\mathrm{O}_{2}$ cost for work-independent processes, SERCA2 KO hearts use more $\mathrm{O}_{2}$ at any given increase in cardiac work (elevated work-dependent $\mathrm{O}_{2}$ consumption), which leads to mechanical inefficiency at high work loads.

Table 2. LV function in ex vivo hearts from SERCA2 FF and SERCA2 $\mathrm{KO}$ mice (4 wk)

\begin{tabular}{lcr}
\hline \hline & SERCA2 FF Mice & SERCA2 KO Mice \\
\hline Number of mice & 15 & \multicolumn{1}{c}{15} \\
Cardiac output, $\mathrm{ml} / \mathrm{min}$ & $16.4 \pm 0.3$ & $12.3 \pm 0.7^{*}$ \\
Coronary flow, $\mathrm{ml} / \mathrm{min}$ & $4.1 \pm 0.2$ & $3.3 \pm 0.2^{*}$ \\
End-diastolic LV pressure, $\mathrm{mmHg}$ & $5.2 \pm 0.3$ & $2.5 \pm 0.2^{*}$ \\
End-systolic LV pressure, mmHg & $74.7 \pm 1.3$ & $61.8 \pm 1.0^{*}$ \\
End-diastolic LV volume, ml & $73.3 \pm 2.7$ & $50.6 \pm 2.9^{*}$ \\
End-systolic LV volume, ml & $33.7 \pm 2.5$ & $22.0 \pm 1.9^{*}$ \\
$\mathrm{dP} / \mathrm{d} t_{\max }, \mathrm{mmHg} / \mathrm{s}$ & $4,984 \pm 92$ & $2,722 \pm 95^{*}$ \\
$\mathrm{dP} / \mathrm{d} t_{\min }, \mathrm{mmHg} / \mathrm{s}$ & $-4,031 \pm 81$ & $-2,490 \pm 93^{*}$ \\
$\mathrm{LV}$ relaxation time constant, $\mathrm{ms}$ & $17.5 \pm 0.4$ & $25 \pm 1.0^{*}$ \\
\hline
\end{tabular}

Values are means \pm SE. Cardiac function was measured in isolated perfused hearts paced at $7 \mathrm{~Hz}$, and steady-state parameters were obtained at preand and afterload values of 10 and $50 \mathrm{mmHg}$, respectively. LV pressures and volumes at end diastole and end systole as well as maximum positive and negative first derivatives of $\mathrm{LV}$ pressure $\left(\mathrm{dP} / \mathrm{d} t_{\max }\right.$ and $\left.\mathrm{dP} / \mathrm{d} t_{\min }\right)$ and $\mathrm{LV}$ relaxation time constants were obtained using a pressure-volume catheter. ${ }^{*} P<0.05$ vs. SERCA2 FF mice. 


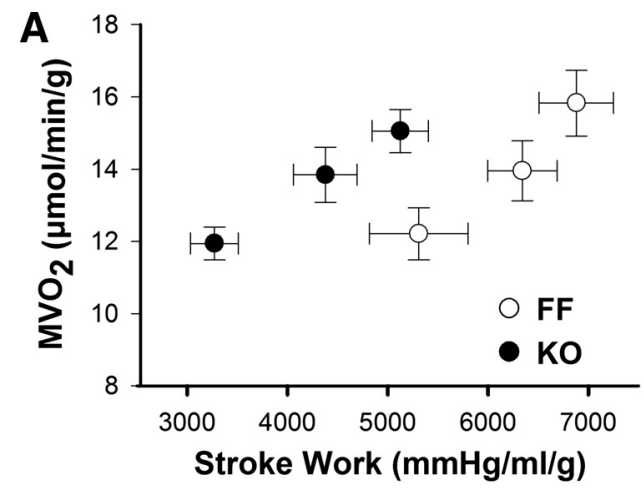

B

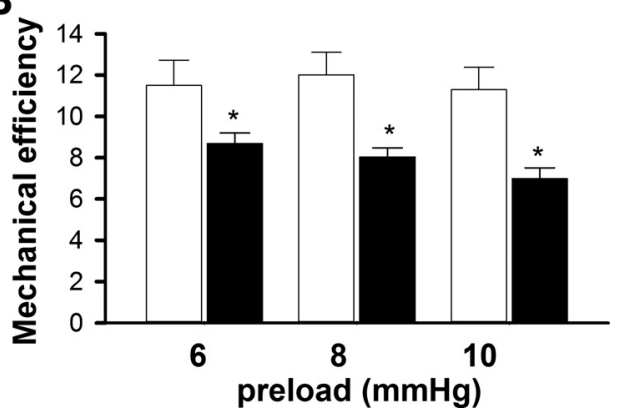

Fig. 2. A: relationship between myocardial $\mathrm{O}_{2}$ consumption $\left(\mathrm{MV}_{2}\right)$ and stroke work at three different workloads (preload: 6,8 , and $10 \mathrm{mmHg}$; afterload: 50 $\mathrm{mmHg})$ in SERCA2 FF $(n=9)$ and SERCA2 $\mathrm{KO}(n=9)$ mice 4 wk after Serca2 gene excision. $B$ : calculated mechanical efficiency (ratio between stroke work and $\mathrm{MVO}_{2}$ ), given in \% by converting both parameters to the same work unit (joules). Values are means \pm SE. $* P<0.05$ vs. SERCA2 FF mice.

Due to the limited working capacity in hearts from SERCA2 $\mathrm{KO}$ mice at the 7-wk time point, we were not able to assess PVA or stroke work in these hearts. However, we did observe reduced $\mathrm{MV}_{2}$ unloaded $(4.2 \pm 0.5$ vs. $3.1 \pm 0.3, P=0.056)$ and $\mathrm{MV}_{\mathrm{O}_{2}} \mathrm{ECC}(3.3 \pm 0.4$ vs. $2.3 \pm 0.2, P=0.033)$ at the 7 -wk time point. It should be noted, however, that the power of this analysis was low, due to the limited number of hearts available.

Myocardial substrate uptake and oxidation. Measurements of myocardial glucose and fatty acid oxidation in isolated perfused working hearts revealed that the decreased cardiac work performed by SERCA2 KO hearts at 4 wk was accompanied by reduced fatty acid and glucose oxidation rates compared with hearts from SERCA2 FF mice (Fig. 4A). When substrate utilization was adjusted for differences in cardiac output, the metabolic rates were similar in the two groups of hearts (Fig. 4B). Substrate utilization at the 7-wk time point was not possible due to the lack of functional capacity of these hearts.

Finally, in vivo myocardial glucose uptake was assessed in a group of SERCA2 KO and SERCA2 FF mice at $5 \mathrm{wk}$ after tamoxifen injection using microPET and ${ }^{18} \mathrm{FDG}$. To verify similar ${ }^{18}$ FDG injection within the two groups, brain FDG uptake was determined, and no differences were detected $(188 \pm 14$ vs. $207 \pm 12, P>0.05$; Fig. 5). Cardiac FDG uptake in SERCA2 $\mathrm{KO}$ mice was found to be markedly reduced compared with SERCA2 FF mice ( $78 \pm 9$ vs. $141 \pm 23, P<0.05)$, indicating that Serca2 excision also results in a reduced myocardial glucose uptake in vivo.

\section{DISCUSSION}

By analyzing LV function and the relationship between mechanical work and $\mathrm{MVO}_{2}$ in hearts from conditional cardiacspecific SERCA2 KO mice, we directly measured how SERCA2 elimination influences mechanical function as well as energetic features of the heart. The present study shows that the reported decrease in the $\mathrm{Ca}^{2+}$ transient amplitude in cardiomyocytes from SERCA2 KO mice (3) is accompanied by a decreased energy cost of ECC. As these hearts, however, show a marked decrease in the efficiency of the chemomechanical energy transduction (contractile efficiency), working hearts from cardiac-specific SERCA2 KO mice were found to be mechanically inefficient.

The effect of reduced activity and/or expression of SERCA2 in the cardiomyocyte will have major implications for ECC and thus contractile function of the heart. Accordingly, $\mathrm{Ca}^{2+}$ transients measured in isolated cardiomyocytes from SERCA2 KO mice have decreased amplitude and longer decay rates as early as 6 days after gene excision (38), changes that become more

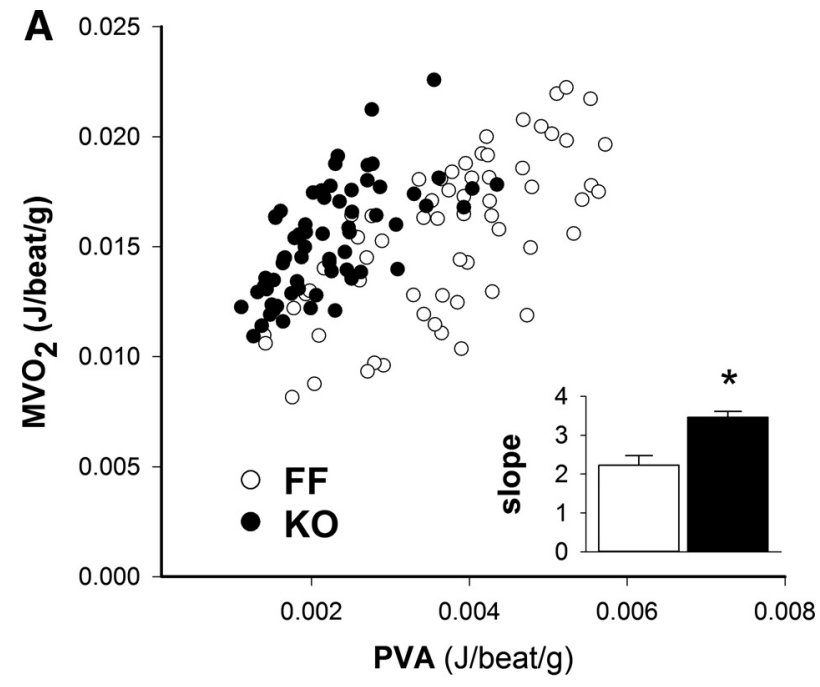

B

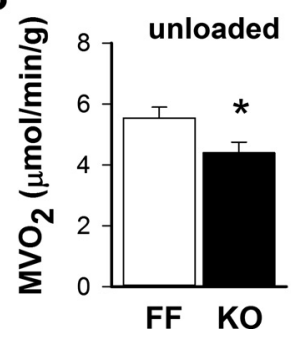

BM

ECC

Fig. 3. To elucidate underlying mechanisms contributing to decreased mechanical efficiency, we evaluated the mechanoenergetic properties of hearts from SERCA2 FF and SERCA2 KO mice 4 wk after Serca2 gene excision. The relationship between pressure-volume area (PVA) and $\mathrm{MV}_{2}$ was measured at different workloads $(A)$, and $\mathrm{MV}_{2}$ was measured in retrogradely perfused unloaded and electrically paced hearts before and after electrical arrest $(B)$. The bars in the inset in $A$ are the group means $(n=9$ SERCA2 FF mice and 9 SERCA2 KO mice) of the slope of these relationships and represent workdependent $\mathrm{O}_{2}$ consumption. The $r^{2}$ values were $0.93 \pm 0.01$ and $0.90 \pm 0.02$ for SERCA2 FF and SERCA2 KO mice, respectively. $B: \mathrm{MV}_{2}$ measured before (unloaded) and after $\left[\mathrm{MVO}_{2}\right.$ for basal metabolism $\left.(\mathrm{BM})\right]$ electrical arrest in hearts from SERCA2 FF $(n=11)$ and SERCA2 KO $(n=10)$ mice. The $\mathrm{O}_{2}$ cost for excitation-contraction coupling (ECC) was calculated as the difference between unloaded $\mathrm{MV}_{2}$ and the $\mathrm{MVO}_{2}$ for $\mathrm{BM}$. Values are means \pm SE. $* P<0.05$ vs. SERCA2 FF mice. 

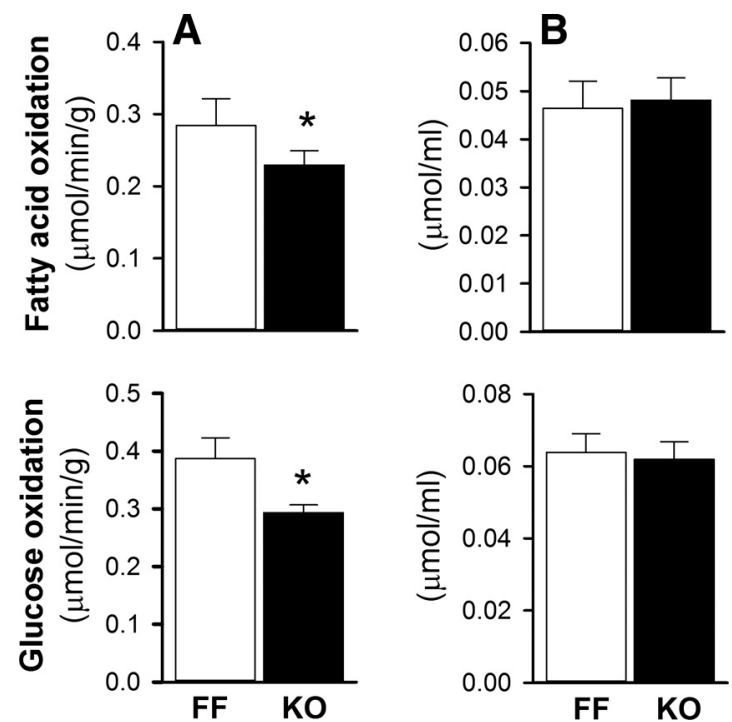

Fig. 4. Myocardial fatty acid and glucose oxidation in SERCA2 FF $(n=10)$ and SERCA2 KO $(n=10)$ mice 4 wk after Serca2 gene excision. $A$ : absolute rates. $B$ : substrate oxidation rates adjusted for differences in cardiac output. Values are means \pm SE. $* P<0.05$ vs. FF.

pronounced when SERCA2 protein is reduced by $95 \%$ at $4 \mathrm{wk}$ after gene excision (3). Despite changes in the $\mathrm{Ca}^{2+}$ transient measured in isolated cells, in vivo cardiac function in 4-wk-old $\mathrm{KO}$ mice has been reported to be relatively well preserved (3, $25)$. At the 6- to 7-wk time point, however, KO mice demonstrate marked in vivo diastolic and systolic dysfunction (3, 14, 25 ), and end-stage heart failure eventually develops, leading to death within a short time period $(3,25)$. In the present study, isolated perfused hearts from SERCA2 $\mathrm{KO}$ mice at $4 \mathrm{wk}$ after gene excision showed marked LV dysfunction, and, at the 7-wk time point, ex vivo SERCA2 KO hearts showed virtually no working capacity. The difference between in vivo and ex vivo cardiac function clearly points to the presence of compensatory systemic changes that support cardiac output in SERCA2 KO mice, such as increased circulating plasma norepinephrine (3). Our findings are further supported by a recent study from Land et al. (21), where it was reported that the low amplitude of the $\mathrm{Ca}^{2+}$ transients observed in $\mathrm{KO}$ cardiomyocytes were insufficient to trigger ventricular ejection when the recorded $\mathrm{Ca}^{2+}$ transients from both 4- and 7-wk KO mice were used in a multiscale computational simulator of the whole heart response. Based on data obtained from $\beta$-adrenergic enhancement of $\mathrm{Ca}^{2+}$ transients, and assuming increased venous return (as a consequence of elevated circulating catecholamine levels and the Frank-Starling effect), Land et al. (21) reported that the simulated P-V loops were comparable with those obtained from in situ experiments. This suggests that the increased $\beta$-adrenergic state contributes to maintain cardiac output in vivo in $\mathrm{KO}$ mice and may also explain why the ex vivo $\mathrm{KO}$ heart (in the absence of $\beta$-adrenergic stimuli and perfused under constant preload conditions) does not demonstrate elevated end-diastolic pressure, as demonstrated in vivo (3). This demonstrates the significance of an evaluation of ex vivo cardiac function to reveal the endogenous properties of the heart per se.

The majority $(>90 \%)$ of ATP production in the heart is derived from mitochondrial oxidative phosphorylation, where fatty acids and glucose represent the main substrates. Although the development of heart failure in animal studies has often been associated with reactivation of the metabolic fetal gene program with decreased fatty acid oxidation and increased glucose utilization (primarily glycolysis), there is still a lack of consensus related to these changes (24), and the causes and consequences of altered myocardial substrate metabolism in heart failure remain unclear. The discrepancy between investigations of substrate metabolism may be attributable to variation between species, the etiology of heart failure, and the progressive state of the disease $(30,37)$. Heart failure in SERCA2 KO mice is associated with reduced glucose uptake in vivo, and ex vivo experiments have demonstrated decreases in both myocardial glucose and fatty acid oxidation. As $\mathrm{KO}$ hearts, however, also demonstrate decreased mechanical function, SERCA2 depletion did not seem to specifically influence the substrate preference for oxidative metabolism.

In the heart, ATP is used both for mechanical and nonmechanical purposes. While a range of studies $(7,32,34)$ have examined the energetic effect of SERCA2 overexpression, the mechanoenergetic consequence of SERCA2 deletion has not previously been examined. Therefore, in the present study, we analyzed the relationship between cardiac work and energy expenditure after the elimination of SERCA2, using $\mathrm{MV}_{2}$ as a measure of energy expenditure. The $\mathrm{O}_{2}$ cost related to nonmechanical processes include ECC, where the energy required for SERCA2 activity corresponds to $\sim 70 \%$ (42). $\mathrm{Ca}^{2+}$ homeostasis in cardiomyocytes from SERCA2 KO mice is dependent on compensatory changes in $\mathrm{Ca}^{2+}$ handling due to the marked reduction in SERCA2 abundance/activity and, consequently, SR $\mathrm{Ca}^{2+}$ content. Accordingly, cardiomyocytes from SERCA2 KO mice show increased protein levels of the L-type $\mathrm{Ca}^{2+}$ channel, sarcolemmal $\mathrm{Ca}^{2+}$-ATPase (PMCA), and NCX1 as well as increased L-type $\mathrm{Ca}^{2+}$ current and NCX1 current density $(3,25,38)$. At the 4 -wk time point, the NKA protein level is unaltered, whereas both the protein level and activity are decreased at $7 \mathrm{wk}$ after gene deletion, changes that are also accompanied by intracellular $\mathrm{Na}^{+}$accumulation (25). A mathematical model, parameterized with the experimentally measured $\mathrm{Ca}^{2+}$ dynamics from control and $\mathrm{KO}$ cardiomyocytes, suggests that the increased L-type $\mathrm{Ca}^{2+}$ and NCX1 currents effectively maintain diastolic and systolic $\mathrm{Ca}^{2+}$ levels after the loss of SERCA2 function (22). Based on the stoichiometry of each $\mathrm{Ca}^{2+}$ transporter, where $\mathrm{SR} \mathrm{Ca}^{2+}$ uptake by SERCA2 has been considered to be most energetically efficient (36), the changes in myocardial $\mathrm{Ca}^{2+}$ handling in SERCA2 KO mice is toward less energetically efficient $\mathrm{Ca}^{2+}$ handling. As

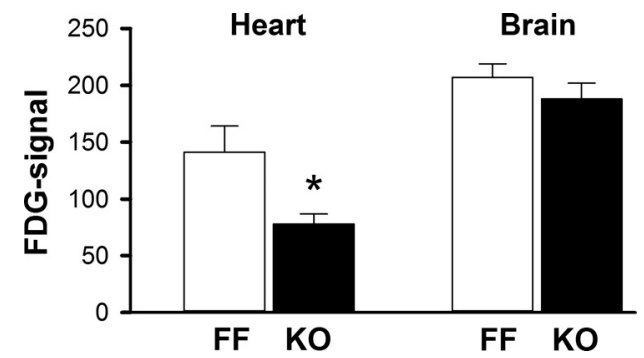

Fig. 5. Myocardial glucose uptake assessed as fluorodeoxyglucose (FDG) uptake with a small animal positron emission tomography scanner in SERCA2 FF $(n=6)$ and SERCA2 KO $(n=5)$ mice $5 \mathrm{wk}$ after Serca 2 gene excision. Values are means \pm SE. $* P<0.05$ vs. SERCA2 FF mice. 
these changes are accompanied by a reduction in the amplitude of the $\mathrm{Ca}^{2+}$ transient, however, it was not clear how this would influence the energy cost for ECC. In a recent study by Li et al. (23), the ATP consumption for ion transport in SERCA2 KO cardiomyocytes was calculated, and, at the 4-wk time point, the reduced ATP requirement for SERCA2 was greater than the increased ATP consumed for NKA or PMCA, and thus the energy used for ion transport was decreased. In accordance with these predictions, we found, by direct measurements, reduced $\mathrm{O}_{2}$ consumption in unloaded SERCA2 KO hearts (work-independent $\mathrm{MVO}_{2}$ ), and this decrease in $\mathrm{MV}_{2}$ was indeed due to a decreased $\mathrm{O}_{2}$ cost for ECC. The mathematical model further predicted that at the 7-wk time point, increased ATP consumption due to the combined rate of increased ATP consumption by NKA and PMCA would be greater than the decrease in ATP consumption by SERCA2. Due to the limited number of hearts in which $\mathrm{O}_{2}$ consumption could be measured, we were not able to firmly determine the work-independent (unloaded) $\mathrm{O}_{2}$ demand in these hearts.

The majority of energy expenditure in the heart is used for contractile activity. As this was not included in the mathematical models by $\mathrm{Li}$ et al. $(22,23)$, we also evaluated the relationship between cardiac work and $\mathrm{MV}_{\mathrm{O}_{2}}$. Despite reduced work-independent $\mathrm{O}_{2}$ consumption and reduced stroke work at a given work load, $\mathrm{MV}_{\mathrm{O}_{2}}$ was not lower in SERCA2 KO hearts, and calculation of the ratio between LV stroke work and $\mathrm{O}_{2}$ consumption showed that SERCA2 KO hearts clearly exhibited mechanical inefficiency. To elucidate the changes that may contribute to this inefficiency, we examined the efficiency of the chemomechanical energy transduction (i.e., contractile efficiency) by examining the relationship between total mechanical energy (assessed as PVA) and $\mathrm{O}_{2}$ consumption $(18,40)$. The slope of this relationship reflects the efficiency of the process of which $\mathrm{O}_{2}$ consumption is converted to ATP synthesis (oxidative phosphorylation) and/or by which ATP hydrolysis is converted to cardiac mechanical work (cross-bridge cycling). In previous studies (7, 32, 34), SERCA2 overexpression has been reported not to alter contractile efficiency, whereas the reduced contractile efficiency after heart failure has been found to be improved by increased SERCA2 expression (35). In the present study, we demonstrated that SERCA2 KO hearts showed reduced contractile efficiency, as the increase in $\mathrm{O}_{2}$ consumption for a given increase in cardiac work (PVA) was significantly higher compared with control hearts. Although the underlying mechanisms are not clear, one could speculate that the reduced SR $\mathrm{Ca}^{2+}$ content and elevated intracellular $\mathrm{Na}^{+}$concentration in cardiomyocytes from $\mathrm{KO}$ mice $(3,23,25)$ can reduce mitochondrial $\mathrm{Ca}^{2+}$ uptake as mitochondrial $\mathrm{Ca}^{2+}$ uptake is most efficient when $\mathrm{Ca}^{2+}$ is released from the SR compared with transsarcolemmal $\mathrm{Ca}^{2+}$ influx $(19,20)$. The reduced mitochondrial $\mathrm{Ca}^{2+}$ uptake may not only hamper activation of the tricarboxylic acid cycle but also (as the redox state of NADH is closely linked to NADPH) reduce the mitochondrial antioxidant capacity and thus increase the emission of hydrogen superoxide (19). As ROS have been shown to activate uncoupling proteins in the mitochondria (13), this could contribute to the reduced efficiency observed in SERCA2 KO hearts. In addition, as the relaxation factor is elevated and thus relaxation is slowed, one may also speculate that the prolonged crossbridge cycling may consume ATP and $\mathrm{O}_{2}$ without a gain in stroke volume (26). Finally, it should also be noted that mechanical inefficiency would be further exacerbated in vivo due to the potential $\mathrm{O}_{2}$ wasting effect after $\beta$-adrenergic stimulation $(10,29,41)$.

In conclusion, the ex vivo evaluation of the mechanical and energetic function of SERCA2 KO hearts in this study brings together experimental and mathematical modeling-based studies and has provided new knowledge on the mechanoenergetic changes after reduced SERCA2 activity. We have demonstrated by direct measurement that, although the decreased amplitude of $\mathrm{Ca}^{2+}$ transients after Serca2 excision results in an overall decreased energy cost of the processes associated with ECC, contractile efficiency (the work-dependent $\mathrm{O}_{2}$ cost) is markedly decreased in these hearts, resulting in mechanical inefficiency.

\section{ACKNOWLEDGMENTS}

The expert technical assistance of Knut Steinnes, Trine Lund, and Elisabeth Boerde is gratefully acknowledged.

\section{GRANTS}

This work was supported by grants from the Norwegian Diabetes Association, Northern Norway Regional Health Authority (Helse Nord RHF), and the Norwegian Heart Association.

\section{DISCLOSURES}

European patent EP 2004808891 (Serca2 Mouse PCT/NO2004/000397) is held by G. Christensen.

\section{AUTHOR CONTRIBUTIONS}

Author contributions: N.T.B. and E.A. conception and design of research; N.T.B., J.M.A., F.W., and E.A. performed experiments; N.T.B., J.M.A., and E.A. analyzed data; N.T.B., J.M.A., W.E.L., I.S., F.W., G.C., O.M.S., and E.A. interpreted results of experiments; N.T.B. and E.A. prepared figures; N.T.B. and E.A. drafted manuscript; N.T.B., W.E.L., I.S., and E.A. edited and revised manuscript; N.T.B., G.C., O.M.S., and E.A. approved final version of manuscript.

\section{REFERENCES}

1. Aasum E, Hafstad AD, Severson DL, Larsen TS. Age-dependent changes in metabolism, contractile function, and ischemic sensitivity in hearts from db/db mice. Diabetes 52: 434-441, 2003.

2. Aghajani E, Nordhaug D, Korvald C, Steensrud T, Husnes K, Ingebretsen O, Revhaug A, Myrmel T. Mechanoenergetic inefficiency in the septic left ventricle is due to enhanced oxygen requirements for excitationcontraction coupling. Cardiovasc Res 63: 256-263, 2004.

3. Andersson KB, Birkeland JA, Finsen AV, Louch WE, Sjaastad I, Wang Y, Chen J, Molkentin JD, Chien KR, Sejersted OM, Christensen G. Moderate heart dysfunction in mice with inducible cardiomyocyte-specific excision of the Serca2 gene. J Mol Cell Cardiol 47: 180-187, 2009.

5. Andersson KB, Finsen AV, Sjaland C, Winer LH, Sjaastad I, Odegaard A, Louch WE, Wang Y, Chen J, Chien KR, Sejersted OM, Christensen G. Mice carrying a conditional Serca2 ${ }^{\text {flox }}$ allele for the generation of $\mathrm{Ca}^{2+}$ handling-deficient mouse models. Cell Calcium 46: 219-225, 2009.

6. Andersson KB, Winer LH, Mork HK, Molkentin JD, Jaisser F. Tamoxifen administration routes and dosage for inducible Cre-mediated gene disruption in mouse hearts. Transgenic Res 19: 715-725, 2010.

7. Belke DD, Swanson E, Suarez J, Scott BT, Stenbit AE, Dillmann WH. Increased expression of SERCA in the hearts of transgenic mice results in increased oxidation of glucose. Am J Physiol Heart Circ Physiol 292: H1755-H1763, 2007.

8. Bing RJ, Hammond MM, Handelsman JC, Powers SR, Spencer FC, Eckenhoff JE, Goodale WT, Hafkenschiel JH, Kety SS. The measurement of coronary blood flow, oxygen consumption, and efficiency of the left ventricle in man. Am Heart J 38: 1-24, 1949. 
9. Boardman N, Hafstad AD, Larsen TS, Severson DL, Aasum E. Increased $\mathrm{O}_{2}$ cost of basal metabolism and excitation-contraction coupling in hearts from type 2 diabetic mice. Am J Physiol Heart Circ Physiol 296: H1373-H1379, 2009.

10. Boardman NT, Larsen TS, Severson DL, Essop MF, Aasum E. Chronic and acute exposure of mouse hearts to fatty acids increases oxygen cost of excitation-contraction coupling. Am J Physiol Heart Circ Physiol 300: H1631-H1636, 2011.

11. Currie S, Smith GL. Enhanced phosphorylation of phospholamban and downregulation of sarco/endoplasmic reticulum $\mathrm{Ca}^{2+}$ ATPase type 2 (SERCA 2) in cardiac sarcoplasmic reticulum from rabbits with heart failure. Cardiovasc Res 41: 135-146, 1999.

12. del MF, Lebeche D, Guerrero JL, Tsuji T, Doye AA, Gwathmey JK, Hajjar RJ. Abrogation of ventricular arrhythmias in a model of ischemia and reperfusion by targeting myocardial calcium cycling. Proc Natl Acad Sci USA 101: 5622-5627, 2004.

13. Echtay KS, Roussel D, St-Pierre J, Jekabsons MB, Cadenas S, Stuart JA, Harper JA, Roebuck SJ, Morrison A, Pickering S, Clapham JC, Brand MD. Superoxide activates mitochondrial uncoupling proteins. Nature 415: 96-99, 2002.

14. Ericsson M, Andersson KB, Amundsen BH, Torp SH, Sjaastad I, Christensen G, Sejersted OM, Ellingsen O. High-intensity exercise training in mice with cardiomyocyte-specific disruption of Serca2. J Appl Physiol 108: 1311-1320, 2010.

15. Gibbs CL, Papadoyannis DE, Drake AJ, Noble MI. Oxygen consumption of the nonworking and potassium chloride-arrested dog heart. Circ Res 47: 408-417, 1980.

16. Hafstad AD, Boardman NT, Lund J, Hagve M, Khalid AM, Wisloff U, Larsen TS, Aasum E. High intensity interval training alters substrate utilization and reduces oxygen consumption in the heart. $J$ Appl Physiol 111: 1235-1241, 2011.

17. Hougen K, Aronsen JM, Stokke MK, Enger U, Nygard S, Andersson KB, Christensen G, Sejersted OM, Sjaastad I. Cre-loxP DNA recombination is possible with only minimal unspecific transcriptional changes and without cardiomyopathy in $\operatorname{Tg}(\alpha$ MHC-MerCreMer $)$ mice. Am $J$ Physiol Heart Circ Physiol 299: H1671-H1678, 2010.

18. How OJ, Aasum E, Kunnathu S, Severson DL, Myhre ES, Larsen TS. Influence of substrate supply on cardiac efficiency, as measured by pressure-volume analysis in ex vivo mouse hearts. Am J Physiol Heart Circ Physiol 288: H2979-H2985, 2005.

19. Kohlhaas M, Liu T, Knopp A, Zeller T, Ong MF, Bohm M, O'Rourke B, Maack C. Elevated cytosolic $\mathrm{Na}^{+}$increases mitochondrial formation of reactive oxygen species in failing cardiac myocytes. Circulation 121: 1606-1613, 2010.

20. Kohlhaas M, Maack C. Adverse bioenergetic consequences of $\mathrm{Na}^{+}-$ $\mathrm{Ca}^{2+}$ exchanger-mediated $\mathrm{Ca}^{2+}$ influx in cardiac myocytes. Circulation 122: 2273-2280, 2010.

21. Land S, Louch WE, Niederer SA, Aronsen JM, Christensen G, Sjaastad I, Sejersted OM, Smith NP. Beta-adrenergic stimulation maintains cardiac function in Serca2 knockout mice. Biophys $J$ 104: 1349 1356, 2013.

22. Li L, Louch WE, Niederer SA, Andersson KB, Christensen G, Sejersted OM, Smith NP. Calcium dynamics in the ventricular myocytes of SERCA2 knockout mice: a modeling study. Biophys $J$ 100: 322-331, 2011.

23. Li L, Louch WE, Niederer SA, Aronsen JM, Christensen G, Sejersted OM, Smith NP. Sodium accumulation in SERCA knockout-induced heart failure. Biophys $J$ 102: 2039-2048, 2012.

24. Lopaschuk GD, Ussher JR, Folmes CD, Jaswal JS, Stanley WC. Myocardial fatty acid metabolism in health and disease. Physiol Rev 90: 207-258, 2010.

25. Louch WE, Hougen K, Mork HK, Swift F, Aronsen JM, Sjaastad I, Reims HM, Roald B, Andersson KB, Christensen G, Sejersted OM. Sodium accumulation promotes diastolic dysfunction in end-stage heart failure following Serca2 knockout. J Physiol 588: 465-478, 2010.

26. Meyer M, Keweloh B, Guth K, Holmes JW, Pieske B, Lehnart SE, Just H, Hasenfuss G. Frequency-dependence of myocardial energetics in failing human myocardium as quantified by a new method for the measurement of oxygen consumption in muscle strip preparations. J Mol Cell Cardiol 30: 1459-1470, 1998.

27. Meyer M, Schillinger W, Pieske B, Holubarsch C, Heilmann C, Posival H, Kuwajima G, Mikoshiba K, Just H, Hasenfuss G. Alterations of sarcoplasmic reticulum proteins in failing human dilated cardiomyopathy. Circulation 92: 778-784, 1995.

28. Muller OJ, Lange M, Rattunde H, Lorenzen HP, Muller M, Frey N, Bittner C, Simonides W, Katus HA, Franz WM. Transgenic rat hearts overexpressing SERCA2a show improved contractility under baseline conditions and pressure overload. Cardiovasc Res 59: 380-389, 2003.

29. Muller S, How OJ, Jakobsen O, Hermansen SE, Rosner A, Stenberg TA, Myrmel T. Oxygen-wasting effect of inotropy: is there a need for a new evaluation? An experimental large-animal study using dobutamine and levosimendan. Circ Heart Fail 3: 277-285, 2010.

30. Nickel A, Loffler J, Maack C. Myocardial energetics in heart failure. Basic Res Cardiol 108: 358, 2013.

31. O'Donnell JM, Pound K, Xu X, Lewandowski ED. SERCA1 expression enhances the metabolic efficiency of improved contractility in postischemic heart. J Mol Cell Cardiol 47: 614-621, 2009.

32. Pinz I, Tian R, Belke D, Swanson E, Dillmann W, Ingwall JS. Compromised myocardial energetics in hypertrophied mouse hearts diminish the beneficial effect of overexpressing SERCA2A. J Biol Chem 286: 10163-10168, 2011.

33. Razeghi P, Young ME, Alcorn JL, Moravec CS, Frazier OH, Taegtmeyer H. Metabolic gene expression in fetal and failing human heart. Circulation 104: 2923-2931, 2001.

34. Sakata S, Lebeche D, Sakata N, Sakata Y, Chemaly ER, Liang LF, Takewa Y, Jeong D, Park WJ, Kawase Y, Hajjar RJ. Targeted gene transfer increases contractility and decreases oxygen cost of contractility in normal rat hearts. Am J Physiol Heart Circ Physiol 292: H2356-H2363, 2007.

35. Sakata S, Lebeche D, Sakata N, Sakata Y, Chemaly ER, Liang LF, Tsuji T, Takewa Y, del MF, Peluso R, Zsebo K, Jeong D, Park WJ, Kawase Y, Hajjar RJ. Restoration of mechanical and energetic function in failing aortic-banded rat hearts by gene transfer of calcium cycling proteins. J Mol Cell Cardiol 42: 852-861, 2007.

36. Shimizu J, Yamashita D, Misawa H, Tohne K, Matsuoka S, Kim B, Takeuchi A, Nakajima-Takenaka C, Takaki M. Increased $\mathrm{O}_{2}$ consumption in excitation-contraction coupling in hypertrophied rat heart slices related to increased $\mathrm{Na}^{+}-\mathrm{Ca}^{2+}$ exchange activity. J Physiol Sci 59: 63-74, 2009.

37. Stanley WC, Recchia FA, Lopaschuk GD. Myocardial substrate metabolism in the normal and failing heart. Physiol Rev 85: 1093-1129, 2005.

38. Stokke MK, Hougen K, Sjaastad I, Louch WE, Briston SJ, Enger UH, Andersson KB, Christensen G, Eisner DA, Sejersted OM, Trafford AW. Reduced SERCA2 abundance decreases the propensity for $\mathrm{Ca}^{2+}$ wave development in ventricular myocytes. Cardiovasc Res 86: 63-71, 2010.

39. Suarez J, Gloss B, Belke DD, Hu Y, Scott B, Dieterle T, Kim YK, Valencik ML, McDonald JA, Dillmann WH. Doxycycline inducible expression of SERCA2a improves calcium handling and reverts cardiac dysfunction in pressure overload-induced cardiac hypertrophy. Am $J$ Physiol Heart Circ Physiol 287: H2164-H2172, 2004.

40. Suga H. Ventricular energetics. Physiol Rev 70: 247-277, 1990.

41. Suga H, Hisano R, Goto Y, Yamada O, Igarashi Y. Effect of positive inotropic agents on the relation between oxygen consumption and systolic pressure volume area in canine left ventricle. Circ Res 53: 306-318, 1983.

42. Takaki M, Tachibana H, Hata Y, Sakamoto T, Suga H. Mechanoenergetics of rat left ventricles in in situ and excised blood-perfused hearts and in unloaded rat left ventricular slices. Heart Vessels Suppl 12: 100-102, 1997.

43. Yu X, Inesi G. Variable stoichiometric efficiency of $\mathrm{Ca}^{2+}$ and $\mathrm{Sr}^{2+}$ transport by the sarcoplasmic reticulum ATPase. J Biol Chem 270: 4361-4367, 1995. 